\title{
E-government design research: Towards the policy-ingrained IT artifact
}

\author{
Göran Goldkuhl \\ Journal Article
}

\section{Tweet}

N.B.: When citing this work, cite the original article.

Original Publication:

Göran Goldkuhl , E-government design research: Towards the policy-ingrained IT artifact, Government Information Quarterly, 2016. 33(3), pp.444-452.

http://dx.doi.org/10.1016/j.giq.2016.05.006

Copyright: Elsevier

http://www.elsevier.com/

Postprint available at: Linköping University Electronic Press

http://urn.kb.se/resolve?urn=urn:nbn:se:liu:diva-132494

(@) $\odot \Theta \Theta$ 


\title{
E-Government Design Research: Towards the Policy-ingrained IT artifact
}

\author{
Göran Goldkuhl \\ Department of Management and Engineering \\ Linköping University \\ Sweden \\ goran.goldkuhl@liu.se
}

\begin{abstract}
This paper investigates whether design research in e-government should be conducted in some special way compared with standard models for design research. It reviews literature in egovernment and design research in order to generate an answer to this research question. The result of this review affirms that the policy character of e-government should determine the way that such design research is conducted. A tentative e-government design research model, consisting of different activities is formulated. This model consists of the following activities: theorizing, policy analysis, workpractice analysis, co-design and co-evaluation of IT artifact and workpractice. Three specific e-government design research principles are formulated: The policy principle, the co-design principle and the theorizing principle. One important result from this paper is the formulation of the concept of the policy-ingrained artifact as an important empirical outcome from e-government design research. A design research case study on social welfare allowances has been used for the generation as well as the validation of the proposed egovernment design research model.
\end{abstract}

Keywords: e-government, design research, design science, policy, information system, IT artifact, co-design, design theorizing 


\section{Introduction: background, purpose and procedure}

Design research has gained a great popularity in many fields of information system (IS). This kind of research is distinguished from classical research of descriptive and explanatory character. Design research is featured by its orientation to the design and creation of new artifacts (Simon, 1996; Hevner at al, 2004). E-government (public sector ICT) is one field with a growing interest for design research. However, most research in e-government seems to be about "what is", i.e. studies of existing states of IS in public administration. Examples of this are broad comparative studies; evaluations of e-government systems; evaluations of e-government programs and also analyses of regulations and policies. There does not yet seem to exist a large body of research in e-government with a distinct design orientation. There may be obstacles from public administrations to let researchers participate in design processes of egov systems. There might also be the case that egov researchers have little knowledge about and experience from design research. General introductions to DR (e.g. Hevner et al, 2004, Peffers et al, 2007) do not state anything specific about how to apply DR in e-government.

This paper is based on the interest to enhance design research in e-government. A key assumption is that there is a great potential of design research in e-government just as it is in other IS fields of application. The initial inquiry stance was that there might be a knowledge need to promote DR in e-government. Hence, the main purpose of this paper is to investigate design research in e-government. A number of closely related research questions follow from this purpose: Should e-government design research be conducted in some special way or can it apply to general models of IS design research? Are there certain reasons for a special way to conduct DR in egov research? In what ways can e-government DR be said to differ from general IS DR? 
These questions have been addressed through a design oriented approach. A model of egovernment design research will be presented (below in section 4) as a response to the stated research questions. The creation of this model is based on the following activities:

- An investigation of models and concepts in general design research (section 2.1)

- A clarification of distinctive features of egov research (section 2.2)

- A review of extant egov design research (section 2.3)

- An investigation of a conducted egov design research case (section 3)

The e-government design research model, which is presented in this paper, is thus based on 1) knowledge about DR, 2) knowledge about egov and 3) knowledge about the intersection of DR and egov. This last issue is addressed through both theoretical studies (literature review) and the author's own empirical work. The author has extensive experiences of egov DR. One case is brought into this paper as an empirical example of egov DR (a case concerning social welfare allowances). This case has the double functions of being 1) an inspirational and generative base and 2) a validation example for the egov DR model. As a complement to this, an investigation of four published egov DR case studies have been conducted in order to assess the Egov DR model's usefulness.

The main idea of this paper is therefore to investigate e-government design research as a subclass of the general class design research. The attempt to clarify features of this sub-class will lead to a specification of those features that are distinctive in relation to the super-class and other sub-classes. However, this inquiry might also lead to an articulation of features that are valid for the super-class (general DR) and possibly also for other sub-classes. A clarification of features that are seen as valid for the super-class design research is a by-product of this inquiry and it is 
beyond the scope of this paper to make a sharp differentiation between the distinctive and the general features of e-government design research. The message of the paper is that there are some distinct features that call for a special treatment of design research in e-government.

\section{Prior research - overview}

\subsection{Design research}

Design research has been contrasted to behavioral research (Hevner et al, 2004). Behavioral research is explanation-oriented research aiming to describe "what is". This can include predictions, but these are purely based on explanations about what is. Predictions are about "what will be" based on what we know about the circumstances at state. Behavioral research has its roots in traditional natural and social science, while design research has its roots in engineering research and is based on the dichotomy of the science of the natural vs. the science of the artificial (Simon, 1996). Design research is concerned with the creation of something possible; "what might be" or "what ought to be”. It investigates and creates new artifacts. This is done in order to explore and demonstrate the possibilities of new artifacts.

During the last two decades there has been an articulation and application of a designoriented research paradigm for IS research under labels such as development research, design research, design science and design science research (e.g. Nunamaker et al, 1991; March \& Smith, 1995; Hevner et al, 2004; Hevner \& Chatterjee, 2010). Even if this way of researching has a long tradition in IS, there seems to be a shift in acceptance and legitimacy after the articulation of the design research foundations mentioned above (ibid). Design research means research through design. It is not only research about design. DR means scholarly work through the conduct of design. New knowledge is created through designing new artifacts. This includes the generation of prescriptive knowledge for how to design something. Such knowledge is 
sometimes given the label design theory (Gregor \& Jones, 2007). As indicated above, there is some confusion and controversy how to label this kind of design oriented research. I will use the term design research throughout this paper.

In the seminal work of Hevner et al (2004) a framework for design research in IS has been presented that also includes seven guidelines. DR is meant to contribute to both practical needs and to the knowledge base of science. The design of a new artifact through DR is made as a response to business needs in the practice environment and it is also based on the application of knowledge derived from the scientific knowledge base. The core of design research is described as a build - evaluate cycle. An artifact is designed through a series of build and evaluate iterations.

Peffers et al (2008) have presented a process model for design research. This model is based on a synthesis of several other process proposals. The suggested DR process consists of six subsequent activities: 1) problem identification and motivation, 2) define the objectives for a solution, 3) design and development, 4) demonstration, 5) evaluation and 6) communication. This six-stage process model expands the build - evaluate cycle of Hevner et al (2004). Two initial activities are placed before any build/design occurs; the identification of problems in practice and the definition of objectives for the solution. Demonstration means to test the proposed artifact in some setting and this activity is inserted between build/develop and evaluate. A final activity consisting of communication to researchers and other audiences has also been added.

Another DR process model has been suggested by Sein et al (2011). They have developed an approach that integrates design research and action research under the label of action design research (ADR). Their purpose has been to broaden DR from narrow techno-centric views. They 
present a four stage model: 1) problem formulation, 2) building, intervention and evaluation, 3) reflection and learning and 4) formalization of learning. This process model can thus be seen as a synthesis of DR models and action research models (as e.g. Susman \& Evered, 1978; Davison et al, 2004). One key principle in ADR is the "theory-ingrained artifact". Sein et al (2011) emphasize that DR should be theory-informed. This means that the built artifact should incorporate certain characteristics that are based on theories, which have informed the design process. One important influence from action research is the emphasis on reflection and learning. Sein et al (2011) also stress the importance of generalized outcomes in terms of design principles. This is done in contrast to the work of Hevner et al (2004) who are somewhat reluctant to include theoretical results from DR. In the view of Hevner et al, the main outcome from design research is the IT artifact; "the result of design-science research in IS is, by definition, a purposeful IT artifact created to address an important organizational problem” (ibid p 82). This can also be said to be one way to follow the call for more emphasis on the IT artifact as expressed by Orlikowski \& Iacono (2001). As described by these authors (ibid), there can be different views of the IT artifact; more narrow techno-centric views (like a computational view) and broader, more socially sensitive views (like the "ensemble view"). More will be said on these issues below.

In the writings of e.g. Hevner et al (2004) and Peffers et al (2008), design research has an emphasis on the concrete design process. There are several scholars who have argued for a more explicit theorizing activity within DR; e.g. Venable (2006), Goldkuhl \& Lind (2010), Lee et al (2011), Kuechler \& Vaishnavi (2012) and Winter (2014). It is, however, not only the case that the design process should be theory-informed. The DR process should include theorizing in order to create theoretical outcomes. In the ADR process model (Sein et al, 2011), the activities of 
reflection and learning indicate the importance of abstraction and theorizing. In the model of Peffers et al (2008) it is only “communication” that indicates this kind of abstraction. In contrast to these more linear models, two-layered frameworks have been presented by Goldkuhl \& Lind (2010) and Lee et al (2011), distinguishing the concrete design process from theorizing activities. Inspired by these scholars such a two-layered design research model is depicted in figure 1 .

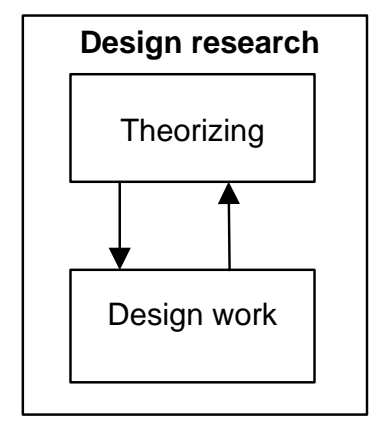

Figure 1. A two-layered design research model

In the ADR approach to design research, Sein et al (2011) argue for a broader perspective on the IT artifact based on the ensemble view of Orlikowski \& Iacono (2001). In such a view, the IT artifact is seen as 1) embedded in a social context and 2) as a carrier of its social context (ibid; Goldkuhl, 2013). The artifact is seen as a carrier of institutional elements derived from its social context.

\subsection{Salient features of e-government}

In order to investigate the grounds for a specific e-government design research approach it is necessary to identify salient features of e-government. The research area of e-government is here conceived of as an intersection of information systems and public administration (Heeks \& Bailur, 2007; Scholl, 2006). 
I will take the e-government evolution model of Janowski (2015) as a vantage point for this discussion. This is not primarily for its discussion of different evolutionary levels, but rather its attempt to identify key characteristics of egov as driving forces for the evolution; cf. also similar discussions in Belanger \& Hiller (2006) and Beynon-Davies (2007). Janowski (2015) starts with a distinction of whether digitization affects the internal working structures of government or not. The use of IT artifacts will often change the way internal processes are carried out. Transformation is seen as a fundamental feature of egov and Janowski (2015) identifies different ranges of such transformation; from 1) internal working structures of single authorities to 2) interaction with other agencies (often called G2G), or 3) interaction with citizens or other actors (often called G2C or G2B) or 4) transformation of a societal sector.

The influence of IT artifacts on governmental working structures is touched upon by several authors; e.g. Lenk (2007). In relation to egov research, Lenk (2007) asserts a demand that "two black boxes have to be opened: the nature of 'ICT', and the nature of the work of public administration at its operative level where it 'executes' public policies and where the menial tasks of public governance are carried out” (ibid p 207f). This demand is explicit concerning 1) the need to understand operational processes and 2) the need to see such work processes as executions of public policy. I will follow these two threads below. There is an interest among several egov scholars how the introduction of IT will enable an improvement of governmental business processes; e.g. Andersen (2002), Scholl (2003), Becker et al (2006), Hughes et al (2006), Weerakkody et al (2006), Chourabi et al (2009) and Niehaves \& Plattfaut (2010). This can comprise both the restructuring of work procedures and the relations to other stakeholders (Janssen \& Cresswell, 2005; Axelsson et al, 2013; Cook \& Harrison, 2015). A process 
management approach in egov implies often addressing, in a combined way, the generic goals of more efficient governmental processes and better services to citizens (Grönlund \& Horan, 2004).

The public policy dimension in egov initiatives is often considered as a fundamental characteristic. A salient feature of e-government is the role of political governance (Peristeras et al, 2002; Grönlund \& Horan, 2004; Fountain, 2005; Yildiz, 2007). What is done in public administration is based on legal regulations and policy declarations. There is no IT artifact in egovernment that does not have any relation to policy of some kind. Egov artifacts apply and build on legal acts and other regulations (e.g. Janssen \& Cresswell, 2005; Allouache \& Khadraoui, 2011; Knackstedt et al, 2012; Cordella \& Tempini, 2015) which make them into “legal machines”.

Public policy is not only a legal issue. There exist many normative issues and concerns that have not been codified in legal documents. Even if there is a great overlap between legal and normative issues in public administration, we need to address these two issues explicitly. The use of IT in public administration can be seen to be a process of value implementation (Fountain, 2001; Flak et al, 2009; Virili \& Sorrentino, 2009; Cordella \& Iannacci, 2010; Persson \& Goldkuhl, 2010; Hellang \& Flak, 2012; Cordella \& Bonina, 2012; Rose et al, 2015; Cook \& Harrison, 2015). The concept of policy is, in this paper, used in an encompassing way covering laws, regulations, policy/strategy declarations, workpractice goals and other value-statements.

Public administration workpractices should follow public policy. Another way to be put it is to say that policy should be institutionalized in work procedures. Institutionalization is not only a top-down process (from policy to workpractice); it can also be a bottom-up process of habitualization of individual actions (Berger \& Luckmann, 1967; Gronow, 2008). Scott (2014) has defined institutions to consist of three pillars: regulative, normative and cultural-cognitive 
elements. There exist suggestions to add a performative dimension to these (Gronow, 2008). This follows also work in egov research (Gil-Garcia \& Martinez-Moyano, 2007) to address issues of how rules influence operational work. There are aspects of language and roles interwoven in Scott's three pillars. In an IS perspective such dimensions should be made explicit as distinct parts. Roles of users/stakeholders should be seen as explicit parts of institutions; i.e. a relational dimension should be added. The same counts for linguistic aspects (information and communication of egov artifacts and in operational work). The linguistic dimension should be made explicit and integrated together with the cognitive. The view of institutions in egov should thus comprise the following inter-related, and partly over-lapping aspects (Goldkuhl \& Nordström, 2014): regulative (“which rules to follow”), normative (“which values to aim at”), cognitive-linguistic ("how to conceive of and talk about things"), performative ("how to conduct work") and relational (“what roles exist”).

There exist a strong institutionally oriented research in egov, e.g. Fountain (2001), Dunleavy et al (2005), Hjort-Madsen (2007), Sawyer \& Tyworth (2007), Alghatam \& Cornford (2012), Cordella \& Contini (2012) and Luna-Reyez \& Gil-Garcia (2014). An institutional orientation means covering IT artifacts and contextual workpractices in an integral manner (Dunleavy et al. 2005; Fedorowicz et al, 2014; Luna-Reyez \& Gil-Garcia, 2014). The object for inquiry and intervention in e-government design research should be said to consist of an institutional reality comprising the IT artifact and its surrounding workpractice context including human actors and the different policies that govern the workpractice and its IT artifacts. A simple model of this is found in figure 2. Egov design researchers should have an interest in if and how policies become institutionalized and thus carried by routinized activities, by public administrators' roles and knowledge and by IT artifacts. Egov design is about transforming policy into IT artifact, work 
processes and stakeholder roles. This policy transformation is a fragile process; sometimes successful (well implemented policies) and sometimes unsuccessful (no implementation of policy elements and/or inappropriate side-effects occurring). It is however also important to acknowledge that institutionalization processes are not to always linear top-down implementation processes. There are negotiations of policy and other institutional aspects between different stakeholders that moderate original policy intentions. Different normative, performative, relational and linguistic elements of institutions evolve gradually within workpractices (Berger \& Luckmann, 1967; Gronow, 2008; Goldkuhl \& Nordström, 2014). Design of IT artifacts and workpractices may be a part a re-institutionalization process, but reinstitutionalization is broader than intentional design since it may also include evolutionary change.

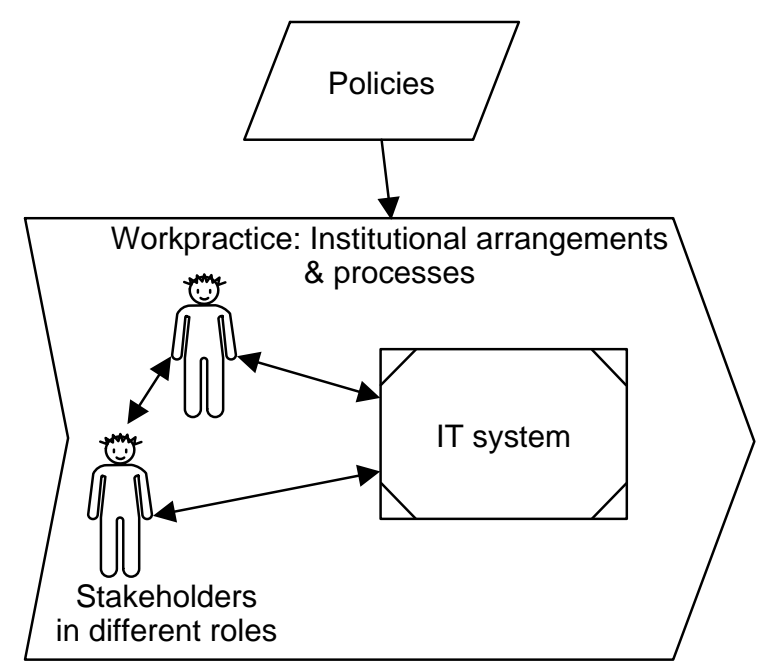

Figure 2. A simple contextual view of e-government

The basic stance taken here is that there are fundamental differences between public administration and private/commercial organizations. This is based on the fact that public agencies (including their IT systems) are parts of societal regulation (Lenk, 2002). This emphasis on differences should not be interpreted as a denial of the existence of certain similarities 
between public agencies and private/commercial firms concerning organizational structure and information systems. There are many studies that have investigated such differences and similarities as well as hybrid forms (e.g. Perry \& Rainey, 1988; Bretschneider, 1990; Rainey \& Boozemann, 2000).

This discussion on salient egov features will be concluded here through an enumeration of typical research interests in such research (informed by the literature review above):

- How work processes may be affected by an egov initiative.

- How transformative an egov initiative will be; i.e. the range of an egov initiative (internal, G2G, G2C, G2B, sectorial).

- How policy (values, regulations) will impact workpractices through an egov initiative; i.e. public policy realization through egov initiatives.

- How different stakeholders will influence an egov initiative and how they will influenced by such an initiative.

- How regulative, normative, cognitive-linguistic, performative, relational and digital dimensions are co-evolving through egov initiatives; i.e. how digitization is dependent on existing institutions and how it is an integral part of institutional development.

\section{$2.3 \quad$ E-government research and design}

Fedorowicz \& Dias (2010) have investigated a ten-year sample of egov papers (from the Annual Digital Government Conference) concerning the use of a design research approach. They conclude that only a minor portion of the papers apply a DR approach, and those that do, rarely position their research explicitly in such terms. "Few digital government studies self-identify as belonging to this research paradigm; others present their technological artifact as a case study 
without grounding in a common methodology or design science framework or theory” (ibid p 6). Fedorowicz \& Dias (2010) used six DR guidelines from Hevner et al (2004) as criteria for further assessing the DR oriented papers. Only a very small portion of papers fulfilled these DR criteria. In total 53 papers of the total sample of 553 papers were considered to have some design research orientation. Out of these 53 papers, there were only four papers that were deemed to fully meet the Hevner DR criteria. These four papers (Chen et al, 2008; Matsunaga et al, 2007; Robertson, 2008; Saleem et al, 2008) will be investigated below in section 5.2.

Fedorowicz \& Dias (2010) have also identified a narrow techno-centric approach among the different DR papers ("few of these papers indicated the contribution of their work beyond the technical benefits of the artifact”; ibid p 6) and they point out the need for egov DR to take a broader social view: "artifact designers are confined by financial, organizational, and political realities that extend beyond technical requirements ... researchers are wise to consider social realities when designing and examining situated artifacts” (ibid p 6). What can be concluded from their study is that 1) there seems to be a need for a specific egov DR approach and 2) the need for such an approach to take a broader social view.

There exist several research endeavors in e-government that have explicitly applied a design research approach, e.g. Karacapilidis et al (2005), Olbrich \& Simon (2008), Liu et al (2007), Chourabi et al (2009), Zwicker et al (2010) and Danneels \& Viaene (2015). Policy has, more or less, been taken into account in these studies. However, there have not been included any discussions in these studies about the challenges in a DR case to apply policy or other aspects specific to the e-government context. Based on an e-government case study, Papas et al (2012) have compared action research and design research, but the contextual features of e-government seem to have been left out from this analysis. 
Meijer \& Bekkers (2015) conducted recently a systematic literature review (a metatheoretical analysis) in order to explore the current research orientations within egov. They divided the research orientations into two main classes; 1 ) research aiming at explaining (mostly with reference to institutional and structural factors) and 2) research aiming at understanding (mostly with reference to individuals’ perceptions and behavior). Their analysis of papers from high-ranked journals (116 papers from 2011-2013) revealed no orientation of papers dealing with design.

The conclusion to be drawn here from the reviews above is that there does not yet exist an articulated design research approach to e-government. There exist egov DR studies; some of them do not identify them as such and those that state that they apply an explicit DR approach have not conducted any specific adaptation of DR to the egov context. It can be claimed to exist a knowledge gap concerning DR in egov research. In order for egov researchers to conduct design research, it might not be sufficient to find scattered examples of egov design research as inspiration. An elaborated egov design research model could guide egov researchers and other IS scholars to conduct such research and to do it with more confidence. As stated above (section 1), the aim of this paper is to contribute to filling this presumed knowledge gap.

\section{An e-government design research case: Social welfare allowances}

The author has participated in several e-government research projects with a design orientation. One case has been selected here to provide deeper information as a generative basis for the formulation of an egov design research model. The selected DR case is from the social welfare sector. It was a fairly complex egov endeavor with many stakeholders involved. Several municipalities participated in a project in order to develop joint digital solutions. These solutions comprise both an e-service application for clients and a multi-query application for collecting 
information about clients from national agencies. A new regulation was launched recently that gives the municipalities better possibilities to obtain information about social welfare clients and it was this new regulation that was the main impetus for starting the project. The handling of client information within the public sector is severely restricted due to data protection regulations. The new regulation stated more clearly what information is permitted to transfer and how to digitally transfer this information to the municipalities. A multi-query software application was developed and launched to the participating municipalities. Information can, on demand, be transferred digitally and immediately from national agencies (like the Social Insurance Agency and the Board for Study Support) to the social welfare offices at the municipalities. This kind of communication was earlier mainly conducted through telephone calls and a slow batch query application.

There were two researchers (including the author) that participated in the project in the capacity of action researchers and design researchers. The integration of action research and design research in this project has been described in Goldkuhl (2012) and Eriksson \& Goldkuhl (2013).. The two researchers have actively conducted different development tasks (like process modelling, information modelling, user-interface design, XML schema design, program coding, testing and deployment) besides traditional research tasks like data collection and analysis. Besides the two researchers, the project team consisted of a professional project leader, public administrators from different municipalities and an IT specialist (IT architect/programmer). The design decisions were made jointly by this project team.

The development work has consisted of different activities, some of which are mentioned below: 
- A detailed legal analysis; both the new regulation and other legal acts (concerning social welfare, data protection and general public administration).

- A study of work procedures and principles of case handling in social welfare allowances.

- A redesign of case processes in order to establish a generic process among the different participating municipalities. It was necessary to find a generic process so that the developed new multi-query application could fit into the different municipalities' workpractices.

- A design of the user-interface of the new multi-query application. This included design of web-pages with information about the legal acts to the users (the social welfare officers). This design was based on a theoretical idea of legal transparency. The user-interface design also included a well-thought design of how to present of the huge amount of information items concerning the clients.

- A design of the data transfer to and from the national agencies, following the information specification of the new regulation. This included also an in-depth investigation of data types from the different legacy systems in the national agencies in order to ensure semantic interoperability.

- A design of identifier management (of individuals and households) in the new multiquery application following institutional principles from social welfare case handling.

The project has resulted in the two new IT artifacts (mentioned above) and changes in the case handling processes. Evaluation has been conducted concerning effects of the use of the artifacts on the case handling process. The researchers have been working with development of 
theoretical results from this DR endeavor with a main focus on creating (design) principles for einfrastructure development in the public sector (Eriksson \& Goldkuhl, 2013).

\section{$4 \quad$ Towards a model for e-government design research}

\subsection{Articulation of a distinct research model for e-government design research}

Based on the review of prior research above several demands can be raised concerning design research in e-government. The vantage point for this analysis is the standard models for design research such as Hevner et al (2004) and Peffers et al (2008). The iterative construct of build/design and evaluate (March \& Smith, 1995; Hevner et al, 2004) seems to be a pivotal element in DR. Hevner et al (2004) claim the importance of the design being founded on practical needs. In Peffers et al (2008), this is operationalized in the first step of the DR process: "problem identification". The analysis of practical needs and problems must, however, be elaborated further than what is done in Hevner et al (2004) and Peffers et al (2008). The emphasis on viewing the IT artifact as contextually embedded as in the ADR approach (Sein et al, 2011) calls for a broader scope. As mentioned above, Lenk (2007) calls for looking into the operational work of public administration. This also follows the business process orientation in egov as well as its focus on institutional aspects (literature mentioned in the review of egov research above; section 2.2). The design approach should be a co-design approach, i.e. codesigning the workpractice and its IT artifact in an integrated way. The outcome of an egov DR endeavor would thus not be limited to just an IT artifact. The outcome would be the combined result of an IT artifact and parallel changes in the workpractice context. As a consequence of this, evaluation should be seen in a similar way as a co-evaluation of the workpractice and the IT artifact. 
Peffers et al (2008) specify the second step in their DR process model as "define the objectives for a solution”. It seems very important in an egov context that this involves a broad investigation of the policy and value background. The analysis must move beyond the immediate problems in the workpractice and derived objectives from such identified problems. An analysis should be performed explicitly directed towards the different policies that are relevant for the workpractice and the IT artifact to be designed; i.e. an analysis of legal acts, regulations, policy declarations and other institutional values. If an egov design is to be a policy implementation process, then an in-depth policy analysis is needed.

As described above, in the review of design research (section 2.1), this kind of research cannot be limited to just a design process. The need for abstraction including the use and generation of theory should be acknowledged. Design research must include theorizing otherwise it cannot be distinguished from plain design. Theoretical constructs should be generated based on the design work, but theory should also be used to inform the design process. Sein et al (2011) have introduced the notion the "theory-ingrained artifact" as a characteristic result from the design research process. In egov DR, the IT artifact should not only be theory-ingrained. We should also talk about the policy-ingrained artifact. This can be said to follow the ideas within the ensemble view of the IT artifact as a contextual carrier (Orlikowski \& Iacono, 2001; Sein et al, 2011; Goldkuhl, 2013). The IT artifact in e-government should be a policy carrier (Cordella \& Iannacci, 2010). There are important distinctions in this respect between a typical egov system and an IT system in a commercial enterprise. The egov system carries policy from outside the specific organization and sometimes also policy from within the organization. Elements from laws and other governing values influencing the specific public agency will transit to the design of the egov system making it a policy carrier. A typical IT system in a business firm will of 
course be influenced by the firm's (internal) goals and policies, but seldom to any large extent by public policy and law.

Several additions and modifications have above been argued for compared with the standard DR models of Hevner et al (2004) and Peffers et al (2008). The conclusions here are that egovernment design research should include:

- Theorizing as an explicit part of DR in order to 1) furnish relevant theoretical governance for design and to 2) generate a theoretical outcome from DR.

- Policy analysis to investigate the policy/value basis for design in order to be able to create a policy-ingrained artifact.

- An explicit workpractice analysis preceding design in order to ensure artifact fit into institutions and business processes.

- Design to be considered as co-design of IT and workpractice.

- Evaluation to be considered as co-evaluation of IT and workpractice.

Based on these extensions, a design research e-government model can now be formulated. Such a model is depicted in figure 3. It is based on the model in figure 1 above. Design work has been unfolded into four activities. 


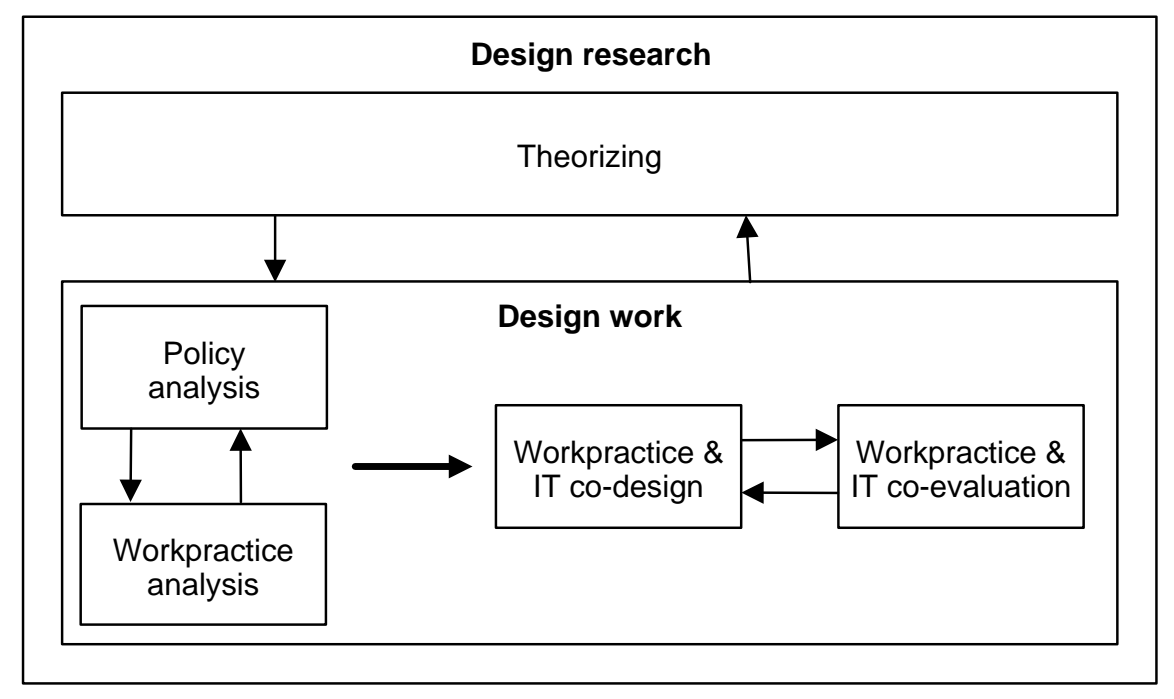

Figure 3. An e-government design research model

\subsection{Comparison with other design research approaches}

This egov design research model (EgovDR) is, in principal, in accordance with the DR guidelines as expressed by Hevner et al (2004); confer, however, further discussion in section 4.3 below. The EgovDR process model is explicitly compared with the DSRM process model of Peffers et al (2008) in table 1 following the discussion above. The different stages of DSRM are compared with the contents, scope and stages of EgovDR.

There are several affinities between this EgovDR model and the ADR model of Sein et al (2011) as indicated above. To work in an integrated manner with IT artifact design and workpractice improvement/intervention is one such commonality. Another one is the view of the IT artifact as a policy carrier (following the ensemble perspective). ADR is a general approach not limited to egov. As such, there are no specific egov characteristics in this approach. There is actually no explicit value analysis in the process model of ADR, which can be compared with the policy analysis of EgovDR. In ADR there is a kind of entanglement of building, intervention and evaluation. In the EgovDR model, evaluation is formulated as a distinct and separate task in concordance with other DR approaches (Hevner et al, 2004; Peffers et al, 2008). The 
entanglement of building and intervention (in ADR) resonates well with the co-design approach of EgovDR. In ADR there is no separate theorizing activity. However, the two concluding reflection and learning phases seem to involve theorizing elements.

Table 1. Comparison between DSRM (of Peffers at al, 2008) and presented e-government design research model

\begin{tabular}{|c|c|}
\hline $\begin{array}{l}\text { DSRM (Peffers et al, } \\
\text { 2008) }\end{array}$ & EgovDR \\
\hline $\begin{array}{l}\text { Problem identification and } \\
\text { motivation }\end{array}$ & $\begin{array}{l}\text { 1) Part of workpractice analysis (identification of workpractice } \\
\text { problems) } \\
\text { 2) Part of theorizing (identification of research problem) }\end{array}$ \\
\hline $\begin{array}{l}\text { Define the objectives for a } \\
\text { solution }\end{array}$ & $\begin{array}{l}\text { Corresponds to Policy analysis, which however is much broader in } \\
\text { scope than just finding objectives for a digital solution. Many possible } \\
\text { aspects of public policy should be investigated. }\end{array}$ \\
\hline Design and development & $\begin{array}{l}\text { Corresponds to workpractice and IT co-design; however DSRM seems } \\
\text { restricted to artifact design. In EgovDR there is prescribed a co-design } \\
\text { approach of IT artifact and workpractice context. EgovDR explicitly } \\
\text { strives for a design of a policy-ingrained artifact. }\end{array}$ \\
\hline Demonstration & This is a test part of workpractice \& IT co-evaluation. \\
\hline Evaluation & $\begin{array}{l}\text { This is a knowledge generation and conclusion part of workpractice \& } \\
\text { IT co-evaluation. The EgovDR approach to evaluation is broader since it } \\
\text { explicitly addresses the workpractice context and its interplay with a } \\
\text { new IT artifact and how public policy is implemented. }\end{array}$ \\
\hline Communication & $\begin{array}{l}\text { This is part of theorizing, which however is defined to explicitly } \\
\text { comprise the creation of abstracted knowledge outcomes. }\end{array}$ \\
\hline
\end{tabular}

\subsection{Three e-government design principles}

The egov design research approach presented in this paper can be summarized into three fundamental principles:

- $\quad$ The policy principle

- $\quad$ The co-design principle

- $\quad$ The theorizing principle

The policy principle expresses the need to base the design in public policy. Procedurally, this is conducted through policy analysis in the EgovDR model, where the policy background (values, 
regulations) is investigated. One major result of an egov DR endeavor should be a policyingrained artifact. The co-design principle expresses the need to make a combined and integrated

analysis and design of the workpractice and the IT artifact. Procedurally, this is expressed in the EgovDR model through workpractice analysis, co-design of workpractice and IT and coevaluation of workpractice and IT. The theorizing principle expresses 1) the need to work in parallel with theorizing during and as a support to the design process and 2) the need to produce explicit theoretical results from design research.

None of these principles can be directly found in the DR guidelines of Hevner et al (2004). Hevner et al (2004) are reluctant to the production of design theory as a result from DR. However, their guideline 4 ("research contributions") comprises, besides the artifact as the main result, conceptual and prescriptive outcomes. This guideline overlaps thus partially with the theorizing principle of EgovDR. The other two (policy, co-design) cannot be found among the Hevner guidelines.

\section{Assessment of the articulated e-government design research model}

\subsection{The social welfare case applied to the e-government design research model}

The described egov DR case (in section 3 above) has, besides the theoretical analyses (section 2), been used as an inspirational source for the formulation of this egov DR model. This means that the case was conducted prior to the formulation of the EgovDR model. However, it is adequate to say that a premature and implicit egov DR model was applied in the welfare case and one result from the case has been an explicit formulation of this model. In this way it resembles the creation and publication of the ADR model (Sein et al, 2001). The empirical basis for ADR (ibid) was a design-oriented action case conducted several years before the articulation of ADR. 
In their publication (ibid) the case has been used retrospectively to illustrate ADR. The same research-methodological approach is thus applied here concerning EgovDR.

I will here make an explicit check that the EgovDR model is in accordance with the conducted social welfare case. This means that this case is here used both 1) as an inspirational basis for formulation of the egov DR model and 2) as a case for an initial empirical validation.

Policy (in terms of different legal acts and principles and values of social welfare work) has had a great impact on the design of the two IT artifacts. Policy analysis has been an important activity in the DR process. The different legal acts and other policy declarations concerning social welfare and data protection have been investigated. The developed multi-query application can definitely be seen as a policy-ingrained artifact. There are several features of the multi-query application that makes it into a policy-ingrained IT artifact: 1) It carries information about legal acts (reachable through the user interface). 2) The information content concerning clients (digitally transferred from national agencies to municipal welfare offices and based on an XML schema) is in direct accordance with the new regulation. 3) Security mechanisms have been established, which direct the users to only submit queries on households which have open welfare cases. This was an important demand in the legal pre-study of the new statute. 4) The identity management follows the institutions of social welfare case handling. The policy principle of EgovDR can thus be said to be applied in this case.

A workpractice analysis of existing social welfare case handling and its institutional character was an important knowledge basis for a new design. This analysis has been transformed into a design of a new generic process for social welfare allowances. The process redesign has been conducted concomitantly with the IT artifact design, which makes it adequate to talk about a co-design of workpractice and IT (thus following the EgovDR principle of co- 
design). An evaluation was conducted that involved an investigation about the interplay between the IT artifact and the workpractice, i.e. a kind of co-evaluation.

Continual theorizing played an important part during this research endeavor. Different models and methods for workpractice evaluation and design were adapted and furnished to the design work (from design theorizing). This means that design theorizing here functioned as a preparatory activity in relation to design work. Continually during the research process, the researchers 1) reflected on observations and 2) performed design interventions and thus 3 ) made different abstractions that were later used both for further design theorizing and further design work. This means that it was a co-constructive and dialectical inter-play between design work and design theorizing. Finally, the researchers have, based on the conducted design interventions, formulated certain design principles for the development of infrastructural digital components in the public sector as a distinct theoretical result of the research (Eriksson \& Goldkuhl, 2013). The theorizing principle of EgovDR can thus be said to be applied in this case.

How would the case look like if these principles of EgovDR had not been applied? This is of course hard to anticipate. If the principles of general DR were applied (following Hevner et al, 2004 and Peffers et al, 2008) then there should not exist any guidance for an in-depth policy analysis or for a workpractice analysis or an imperative to create any theoretical outcome. The result might be limited to just a technical artifact. This artifact might not be an explicit policy carrier as it has become. A generic case handling process would probably not have been developed. This would have made the deployment and implementation processes of the new IT artifacts in different municipalities more difficult. 


\subsection{Assessment of selected e-government design studies}

The three principles of the EgovDR model will be applied here to some conducted egov design studies in order to assess the prescriptive value of these principles. The idea of the EgovDR model is that this approach should give design-oriented scholars support in conducting and publishing their research. A couple of egov design studies have been selected and studied in retrospect using the Egov DR principles as a lens. What can be learned from this examination? If this investigation shows any suggestions for improvements, then this is an indication that the use of EgovDR could ameliorate the performance of egov design research. I have used the four selected exemplar cases from Fedorowicz \& Dias (2010); cf. section 2.3 above. In this examination I have studied each research contribution itself and also studied the examination made by Fedorowicz \& Dias (2010) to obtain a better grounding of the conducted assessment.

The contribution by Chen et al (2008; 2009) is in the area of insurance regulation, more specifically disaster insurance regulation. The authors present a work on developing a "hurricane loss model” in order to assist public administration in assessing insurance companies' insurance rates. In their original paper (Chen et al, 2008), little is said about policy issues. In a later, enhanced journal version of their work (Chen et al, 2009), the policy issues are treated in more detail, with arguments about making "insurance regulation much more transparent” (ibid p 293). In this later paper there is an explicit discussion how the artifact has impacted public policy and insurance policy. Concerning the co-design principle I quote Fedorowicz \& Dias (2010 p 5): "We note that the paper focuses on technical design issues, with little to no discussion of the social context within which the system is to be used.” The most of these papers deal with issues of data integration and what kinds of computational models are used. There is a discussion about 
system integration principles, but I would not characterize this as a contribution to a theoretical discourse of design principles.

Matsunaga et al (2007) describes a SOA-based IT development effort for transnational sharing of immigration information. The paper can be characterized as a software engineering study applied within egov. There is no treatment of policy issues and the discussion about communication processes is restricted to digital transfer. Hence, there is no co-design of IT and workpractice. The paper is a techno-centric design case study and it is hard to find any theorizing ambitions.

Robertson (2008) presents a design study on assisting voters’ online search behavior. A query tool was developed and studied experimentally. This is an explicit design research study with clear focus on human-computer interaction issues. The underlying value is that voters should be better informed and prepared for elections. The tool is built in order to support more knowledgeable voters. The tool and the research study are clearly influenced by this value; i.e. the policy principle is well demonstrated. The query tool seems to have a clear design basis in humans’ search behavior and it can therefore be said to follow the co-design principle. There are discussions on design principles, but further theorizing could be made.

Saleem et al (2008) have proposed a model for pre-disaster preparation and post-disaster support for business continuity and recovery. Based on this model a design and implementation of an IT prototype has been conducted. The authors are clear of what kind of values to support through this IT artifact. A thorough contextual analysis has been conducted giving a clear foundation for the design. The conducted research seems to comply well with the policy and codesign principles. There is no explicit theorizing in the paper. However, it is well structured with a clear conceptual explication. The step to an explicit theorizing is not far away. 
These four papers were selected by Fedorowicz \& Dias (2010) to be the papers that complied most fully with general DR principles (of Hevner et al 2004). When looking at these four egov design papers, it is clear that not all three design research principles are fulfilled for all these papers; the results are summarized in table 2. The papers by Robertson and Saleem et al are close to complying with all principles. The other two papers are not. It is also clear that the principles are fulfilled in varying degrees. One major conclusion is that all papers can be improved, as egov DR papers, if the principles were followed. It is not the case that the papers "automatically", as being egov DR papers, fulfill the principles. It is thus meaningful to have this principles stated explicitly and as a complement to general DR guidelines. This is similar to the conclusions and arguments in Fedorowicz \& Dias (2010). There were several egov papers in their investigation that were design-oriented, but only a small portion adhered to the DR guidelines.

Table 2. Assessment of exemplar DR studies using EgovDR principles (F = Fully met; $\mathrm{P}=$ Partially met; $\mathrm{N}=$ Not met)

\begin{tabular}{|l|c|c|c|c|}
\hline & Policy principle & $\begin{array}{c}\text { Co-design } \\
\text { principle }\end{array}$ & $\begin{array}{c}\text { Theorizing } \\
\text { principle }\end{array}$ & $\Sigma$ \\
\hline Chen et al (2008) & $\mathrm{N}$ & $\mathrm{N}$ & $\mathrm{N}$ & $\mathrm{N}(3)$ \\
\hline $\begin{array}{l}\text { Matsunaga et al } \\
(2007)\end{array}$ & $\mathrm{N}$ & $\mathrm{N}$ & $\mathrm{N}$ & $\mathrm{N}(3)$ \\
\hline Robertson (2008) & $\mathrm{F}$ & $\mathrm{F}$ & $\mathrm{P}$ & $\mathrm{F}(2), \mathrm{P}(1)$ \\
\hline $\begin{array}{l}\text { Saleem et al } \\
(2008)\end{array}$ & $\mathrm{F}$ & $\mathrm{F}$ & $\mathrm{F}(2), \mathrm{P}(1)$ \\
\hline$\Sigma$ & $\mathrm{F} \mathrm{(2),} \mathrm{N} \mathrm{(2)}$ & $\mathrm{F} \mathrm{(2),} \mathrm{N} \mathrm{(2)}$ & $\mathrm{P}(2), \mathrm{N}(2)$ & $\mathrm{F} \mathrm{(4),} \mathrm{P} \mathrm{(2),} \mathrm{N} \mathrm{(6)}$ \\
\hline
\end{tabular}

\section{Conclusions}

This research has been governed by the primary research question "shall design research in egovernment be conducted in some special way?”. This research question has been affirmed through the theoretical and empirical argumentation of this paper. The public policy character of e-government is distinct and should imply consequences for the way egov DR is conducted. 
Policy analysis should be an important part of such design research. This paper follows in the paths of Fedorowicz \& Dias (2010) arguing for more interest among egov scholars for design research. If egov scholars embark on a design research endeavor there are different options: 1) conducting a design-oriented case study without applying any specific DR methodology, 2) applying general and established principles of design research, or 3) applying DR principles especially adapted to the egov domain (for example the EgovDR approach presented here).

When conducting design research within egov, option 3 seems to be the most favorable one. There is a greater risk to not reach desired results if other options are chosen. It is of course possible to reach intended results when applying option 2 and even option 1, but it is in those situations more haphazard to really reach such intended results. This can be compared with the analysis of egov DR papers by Fedorowicz \& Dias (2010). It was possible to adhere to general egov guidelines without explicitly ground the work on them, but not many studies did succeed to comply with these guidelines. The risks of not applying a specific egov DR approach (as presented in this paper) are that policy issues are not sufficiently taken into account in the design process and that a techno-centric approach is applied without sufficiently considering the workpractice and its institutional character and thus the need for a combined IT and work design (Fedorowicz \& Dias, 2010; Fedorowicz et al, 2014; Iivari, 2015; Sein et al, 2011).

The main contributions of this paper are threefold: 1) a description of a suggested egov design research process (the EgovDR model), 2) three principles for the conduct of egov design research and 3) a clarification of the main change outcome from egov design research: The policy-ingrained artifact.

The EgovDR model is based on general DR principles as described in main sources as Hevner et al (2004), Peffers et al (2008) and Sein et al (2011). Certain amendments have been 
done in relation to these DR sources following the investigation of salient egov features and the presented empirical case. The critical analysis of standard models for design research has implied certain improvements that are relevant for egov DR. It is imperative to conduct a policy analysis as a prominent part of such design research (the Egov DR policy principle). It is also important to conduct the design activity in a co-design manner, i.e. a co-design of the workpractice and the IT artifact (the EgovDR co-design principle). The same goes for evaluation, i.e. a co-evaluation of the workpractice and the IT artifact. It is also important to make design theorizing as an explicit part of design research (the EgovDR theorizing principle). This kind of theorizing activity should, however, be distinct and not blurred into design work. Design theorizing and practical design work should work in tandem; mutually contributing to each other.

Design research has contributed with a clear design orientation in IS research. It has also contributed with a separation between deign oriented research and other kinds of research. Hevner et al (2004) have made a well-known distinction between design research and behavioral research. This distinction has been made with the intention to articulate DR as a distinct and separate research approach. However, such a sharp dichotomization is perhaps not healthy for the field. What is called behavioral research is or should, at least, be dealing with design issues. Design, as process and product, is fundamental in information systems and e-government. Design research thinking can contribute to egov research in more ways than through the creation of this specific Egov DR approach and its applications. Design research can in an inspirational way contribute to egov research (of "behavioral research" character) in other ways: 1) Recognizing the design in egov solutions and 2) recognizing the continual management of egov as a process of gradual design and 3) not being afraid of being prescriptive in knowledge 
outcome. This would make the differentiation between what is called design research and behavioral research less sharp.

Future research should apply this presented egov DR model in egov design cases and study its usefulness. Future research should also investigate egov DR studies that have been conducted previously in order to further assess the model and to provide a basis for the further sharpening of such previous egov design research contributions; cf. the analysis in section 5.2 above as examples of this kind of investigation. This means that it should be possible to use this research model retroactively as an evaluation and improvement instrument.

\section{Acknowledgements}

The social welfare design case, used as empirical illustration in this paper, has been conducted with financial support from the Swedish Governmental Agency for Innovation Systems (VINNOVA). The author is very grateful to the editor and the reviewers for demanding and insightful comments.

\section{References}

Alghatam N, Cornford T (2012) Institutional interplay and improvisations in e-government projects, ECIS 2012 Proceedings, Barcelona

Allouache W, Khadraoui A (2011) Strategies to construct e-government services in compliance with legal framework - case study: services dedicated to the Algerian health insurance, Journal of e-Government Studies and Best Practices, Vol 2011

Andersen K V (2002) Public sector process rebuilding using information systems, in. Traunmüller R, Lenk K (Eds. 2002) EGOV 2002, LNCS 2456, p 37-44, Springer, Berlin

Axelsson K, Melin U, Lindgren I (2013) Public e-services for agency efficiency and citizen benefit — Findings from a stakeholder centered analysis, Government Information Quarterly, Vol 30, pp 10-22 
Becker J, Algermissen L, Niehaves B (2006) A procedure model for process oriented egovernment projects, Business Process Management Journal, Vol 12 (1), p 61-75

Belanger F, Hiller J (2006) A framework for e-government: privacy implications, Business Process Management Journal, Vol 12 (1), pp. 48-60

Berger P L, Luckmann T (1967) The social construction of reality, Doubleday \& Co, Garden City

Beynon-Davies P (2007) Models for e-government, Transforming Government: People, Process and Policy, Vol 1 (1), p 7-28

Bretschneider S (1990) Management Information Systems in Public and Private Organizations: An Empirical Test, Public Administration Review, Vol 50 (5), pp 536-545

Chen S-C, Chen M, Zhao N, Hamid S, Saleem K, Chatterjee K (2008) Florida Public Hurricane Loss Model (FPHLM): research experience in system integration, Proceedings of the 2008 international conference on Digital government research

Chen S-C, Chen M, Zhao N, Hamid S, Chatterjee K, Armella M (2009) Florida public hurricane loss model: Research in multi-disciplinary system integration assisting government policy making, Government Information Quarterly, Vol 26, pp 285-294

Chourabi H, Mellouli S, Bouslama F (2009) Modeling e-government business processes: New approaches to transparent and efficient performance, Information Polity, Vol 14, p 91-109

Cook M, Harrison T (2015) Using public value thinking for government IT planning and decision making: A case study, Information Polity, Vol 20, pp 183-197

Cordella A, Bonina C (2012) A public value perspective for ICT enabled public sector reforms: A theoretical reflection, Government Information Quarterly, Vol 29, pp 512-520 
Cordella A, Iannacci F (2010) Information systems in the public sector: The e-Government enactment framework, Journal of Strategic Information Systems, Vol 19, pp 52-66

Cordella A, Tempini N (2015) E-government and organizational change: Reappraising the role of ICT and bureaucracy in public service delivery, Government Information Quarterly, Vol 32, pp 279-286

Danneels L, Viaene S (2015) Simple rules strategy to transform government: An Action Design Research approach, Government Information Quarterly, Vol 32, pp 516-525

Davison R M, Martinsons M G, Kock N (2004) Principles of canonical action research, Information Systems Journal, Vol 14, p 65-86

Dunleavy P, Margetts H, Bastow S, Tinkler J (2005) New Public Management Is Dead - Long Live Digital-Era Governance, Journal of Public Administration Research and Theory, Vol 16, pp 467-494

Eriksson O, Goldkuhl G (2013) Preconditions for public sector e-infrastructure development, Information and Organization, Vol 23 (3), pp 149-176

Fedorowicz J, Dias M (2010) A decade of design in digital government research, Government Information Quarterly, Vol 27, pp 1-8

Fedorowicz J, Sawyer S, Williams C, Markus L, Dias M, Tyworth M, Gantman S, Jacobson D, Tomasino A, Schrier R (2014) Design observations for interagency collaboration, Government Information Quarterly, Vol 31, pp 302-316

Flak L S, Dertz W, Jansen A, Krogstie J, Spjelkavik I, Ølnes S (2009) What is the value of eGovernment - and how can we actually realize it?, Transforming Government: People, Process and Policy, Vol. 3 (3), pp 220-226 
Fountain J (2001) Building the virtual state. Information technology and institutional change, Brooking Institution Press, Washington

Fountain J (2005) Central Issues in the Political Development of the Virtual State, in Castells, M, Cardoso G, (Eds. 2005) The Network Society: From Knowledge to Policy, Johns Hopkins Center for Transatlantic Relations, Washington DC

Gil-Garcia R, Martinez-Moyano I (2007) Understanding the evolution of e-government: The influence of systems of rules on public sector dynamics, Government Information Quarterly, Vol 24, pp 266-290

Goldkuhl G (2012) Pragmatism vs. interpretivism in qualitative information systems research, European Journal of Information Systems, Vol 21 (2), p 135-146

Goldkuhl G (2013) From ensemble view to ensemble artefact - An inquiry on conceptualisations of the IT artefact, Systems, Signs \& Actions, Vol 7 (1), pp. 49-72

Goldkuhl G, Nordström M (2014) Challenges in IT service management: institution vs. improvisation, the 3rd International workshop on IT Artefact Design \& Workpractice Improvement, Friedrichshafen

Goldkuhl G, Lind M (2010) A multi-grounded design research process, in Winter R, Shao L, Aier S (Eds, 2010) DESRIST-2010 Proceedings, LNCS 6105, Springer, Berlin

Gregor S, Jones D (2007) The Anatomy of a Design Theory, Journal of AIS, Vol 8 (5), p 312335

Gronow A (2008) Not by rules or choice alone: a pragmatist critique of institution theories in economics and sociology, Journal of Institutional Economics, Vol 4 (3), pp 351-373

Grönlund Å, Horan T (2004) Introducing e-gov: history, definitions, and issues, Communications of AIS, Vol 15, pp 713-729 
Heeks R, Bailur S (2007) Analyzing e-government research: Perspectives, philosophies, theories, methods, and practice, Government Information Quarterly, Vol 24, p 243-265

Hellang Ø, Flak L S (2012) Assessing effects of egovernment initiatives based on a public value framework, in Scholl H J et al. (Eds. 2012) EGOV 2012, LNCS 7443, Springer, Berlin

Hevner A, Chatterjee S (2010) Design research in information systems. Theory and practice, Springer, New York

Hevner A R, March S T, Park J, Ram S (2004) Design science in information systems research, MIS Quarterly, Vol 28 (1), p 75-115

Hjort-Madsen K (2007) Institutional patterns of enterprise architecture adoption in government, Transforming Government: People, Process and Policy, Vol 1 (4), pp 333-349

Iivari J (2015) Distinguishing and contrasting two strategies for design science research, European Journal of Information Systems, Vol 24, pp 107-115

Janowski T (2015) Digital government evolution: From transformation to contextualization, Government Information Quarterly, Vol 32, pp 221-236

Janssen M, Cresswell A (2005) An enterprise application integration methodology for egovernment, Journal of Enterprise Information Management, Vol. 18 (5), p 531-547

Hughes M, Scott M, Golden W (2006) The role of business process redesign in creating egovernment in Ireland, Business Process Management Journal, Vol. 12 (1), pp 76-87

Karacapilidis N, Loukis E, Dimopoulos S (2005) Computer-supported G2G collaboration for public policy and decision-making, Journal of Enterprise Information Management, Vol 18 (5), pp 602-624

Knackstedt R, Eggert M, Heddier M, Richter, E, Becker J (2012) The relationship of IS and law - insights into the German online car registration case, ECIS 2012 Proceedings, Barcelona 
Kuechler B, Vaishnavi V (2012) A framework for theory development in design science research: Multiple perspectives, Journal of AIS, Vol 13 (6), pp 395-423

Lee J S, Pries-Heje J, Baskerville R (2011) Theorizing in Design Science Research, in Jain H, Sinha A P, Vitharana P (Eds. 2011) DESRIST 2011, LNCS 6629, pp. 1-16, Springer, Berlin

Lenk K (2002) Electronic Service Delivery - A driver of public sector modernisation, Information Polity, Vol 7, p 87-96

Lenk K (2007) Reconstructing Public Administration theory from below, Information Polity, Vol 12, p 207-212

Liu J, Baida Z, Tan Y-H, Korpela K (2007) Design and Analysis of e-Government Control: the Green Corridor between Finland and Russia, 20th Bled eConference, Bled

Luna-Reyez L, Gil-Garcia R (2014) Digital government transformation and internet portals: The co-evolution of technology, organizations, and institutions, Government Information Quarterly, Vol 31, pp 545-555

March S T, Smith G F (1995) Design and natural science research in information technology, Decision Support Systems, Vol 15 (4), pp 251-266

Matsunaga A, Tsugawa M, Fortes J (2007) Integration of text-based applications into serviceoriented architectures for transnational digital government, Proceedings of the 8th annual international conference on Digital government research

Meijer A, Bekkers V (2015) A metatheory of e-government: Creating some order in a fragmented research field, Government Information Quarterly, Vol 32, pp 237-245

Niehaves B, Plattfaut R (2010) From Bureaucratic to Quasi-market Environments: On the Coevolution of Public Sector Business Process Management, in Wimmer M et al. (Eds. 2010) EGOV 2010, LNCS 6228, Springer, Berlin 
Nunamaker J, Chen M, Purdin T (1991) Systems Development in Information Systems Research, Journal of Management Information Systems, Vol 7 (3), p 89-106

Olbrich S, Simon C (2008) Process modelling towards e-government - visualisation and semantic modelling of legal regulations as executable process sets, Electronic Journal of eGovernment, Vol 6 (1), pp 43 - 54

Orlikowski W J, Iacono C S (2001) Desperately seeking the “IT” in IT research - a call to theorizing the IT artifact, Information Systems Research, Vol 12 (2), pp 121-134

Papas N, O’Keefe R, Seltsikas P (2012) The action research vs. design science debate: reflections from an intervention in eGovernment, European Journal of Information Systems, Vol 21 (2), p 147-159

Peffers K, Tuunanen T, Rothenberger M A, Chatterjee S (2007) A design science research methodology for information systems research, Journal of Management Information Systems, Vol 24 (3), p 45-77

Peristeras V, Tsekos T, Tarabanis K (2002) Analyzing e-government as a paradigm shift, UNTC Occasional Papers Series, No 1, United Nations Thessaloniki Centre for Public Service Professionalism

Perry J, Rainey H (1988) The Public-Private distinction in organization theory: A critique and research strategy, Academy of Management Review, Vol 13, (2), pp 182-201

Persson A, Goldkuhl G (2010) Government Value Paradigms - Bureaucracy, New Public Management, and E-Government, Communications of AIS, Vol 2010 (27), p 45-62

Rainey H, Bozeman B (2000) Comparing Public and Private Organizations: Empirical Research and the Power of the A Priori, Journal of Administration Research and Theory, Vol 10 (2), pp 447-469 
Robertson S (2008) Design research in digital government: A query prosthesis for voters, Proceedings of the 2008 international conference on Digital government research

Rose J, Persson J S, Heeager L T (2015) How e-Government managers prioritise rival value positions: The efficiency imperative, Information Polity, Vol 20, pp 35-59

Saleem K, Luis S, Deng Y, Chen, S-C, Hristidis V, Li T (2008) Towards a business continuity information network for rapid disaster recovery, Proceedings of the 2008 international conference on Digital government research

Sawyer S, Tyworth M (2006) E-Government: Contrasting approaches and alternative insights, Pennsylvania State University, Sprouts: Working Papers on Information Systems, 6 (21)

Scholl H J (2003) E-government: A special case of ICT-enabled business process change, Proceedings of the 36th Hawaii International Conference on System Sciences

Scholl H J (2006) Is e-government research a flash in the pan or here for the long shot?, in Wimmer M et al. (Eds.) EGOV 2006, LNCS 4084, Springer, Berlin

Scott W R (2014) Institutions and organizations, $4^{\text {th }}$ Ed, Sage, Thousand Oaks

Sein M, Henfridsson O, Purao S, Rossi M, Lindgren R (2011) Action design research, MIS Quarterly, Vol 35 (1), p 37-56

Simon H A (1996) The sciences of the artificial, MIT Press, Cambridge

Susman G I, Evered R D (1978) An assessment of the scientific merits of action research, Administrative Science Quarterly, Vol 23 (4) p 582-603

Venable J (2006) The Role of Theory and Theorising in Design Science Research, in Proc of DESRIST 2006, Claremont

Virili F, Sorrentino M (2009) Value generation in e-government from service-based IT integration, Transforming Government: People, Process and Policy, Vol 3 (3), pp. 227-247 
Weerakkody V, Baire S, Choudrie J (2006) E-Government: The Need for Effective Process Management in the Public Sector, Proceedings of the 39th Hawaii International Conference on System Sciences, ACM

Winter R (2014) Towards a framework for evidence-based and inductive design in information systems research, Proceedings EDSS-2013, CCIS 447, Springer, Berlin

Yildiz M (2007) E-government research: Reviewing the literature, limitations, and ways forward, Government Information Quarterly, Vol 24, pp 646-665

Zwicker J, Fettke P, Loos P (2010) Business process maturity in public administrations, in vom Brocke J, Rosemann M (eds. 2010) Handbook on Business Process Management 2, Springer, Berlin 